\title{
The Relationship between RMB Exchange Rate and Chinese Trade Balance: Evidence from a Bootstrap Rolling Window Approach
}

\author{
Junaid Masih ${ }^{1}$, Dongsheng Liu ${ }^{1} \&$ Javed Pervaiz ${ }^{2}$ \\ ${ }^{1}$ Department of Mathematics, School of Science, Nanjing University of Science and Technology, Nanjing, \\ Jiangsu, P.R. China \\ ${ }^{2}$ School of Economics, Northeast Normal University, Changchun, Jilin, P.R. China \\ Correspondence: Junaid Masih, Department of Mathematics, School of Science, Nanjing University of Science \\ and Technology, Nanjing, Jiangsu, P.R. China.
}

Received: November 27, 2017

Accepted: December 18, 2017

Online Published: January 5, 2018

doi:10.5539/ijef.v10n2p35

URL: https://doi.org/10.5539/ijef.v10n2p35

\begin{abstract}
This study inspects the fundamental relationship between the exchange rate and the trade balance in China. The outcome shows that the real effective exchange rate and trade balance in China has no causal relationship. Though, seeing structural changes in two series, we got the result those both long-run and short-run associations using full-sample data are wobbly, which proposes that the full-sample causation tests can't be relied upon. Then, using time-varying rolling window method to reexamine the dynamic fundamental relationship. The results show that real effective exchange rate has both negative and positive impacts on the trade balance in several sub-periods, and in turn, trade balance has same impact on real effective exchange rate for China. These findings provide no support for the existence of J-curve effect and Marshall-Lerner Condition in case of China. This study shows that it is impossible to resolve China's trade deficit, depending only on the movement of RMB's exchange rate.
\end{abstract}

Keywords: exchange rate, trade balance, rolling window, bootstrap, time-varying causality

\section{Introduction}

To determine the causal relationship between the exchange rate and trade balance in China is the purpose of this paper. Traditionally, in international trade the exchange rate played a significant role, specifically during era of economic globalization. It is considered that exchange rate policy is one of the powerful tool that has direct effects on trade and indirect effects on investment, business, other sectors of economy and policy decisions. This kind of policy is also used to target and push trade balance in specific direction. From the standpoint of trade balanced elasticity theory, a real currency depreciation improves balance trade, as long as condition Marshall-Lerner is satisfied, while in the short-run, a real devaluation worsens a country's balance trade before leading to an improvement (i.e. effect resembles the letter J, thus called J-curve effect) (Tunaer Vural, 2016). However, there exists a doubt whether TB is affected by appreciation or depreciation in exchange rate. Empirical evidence is slightly mixed and is not much valuable so that the policymakers are unable to direct balance of trade by an impressive tool exchange rate (Koray \& McMillin, 1999). Theory or Literature back that there will be an improvement in TB if Marshal-Lerner condition fulfilled, however it doesn't have enough empirical support because depending upon the economies, it's effect may differ. There is some theoretical justification by J-curve but a lot of empirical evidence still do not support (Petrovic \& Gligoric, 2010). To support or reject the two key phenomena's J-curve and Marshal-Lerner condition, there is a big need to find out the empirical evidence.

Over the past three decades, China has seen an extraordinary economic growth since it implemented some changes and opening up policies in the late 1970s. In term of population China considered as a large economy and also it's more focused on the export-oriented growth for development strategy. China has policy instruments and cheap labor which is the biggest advantages to draw the attention FDI (foreign direct investment), which embracing globalization of production by utilizing them. China became "World Factory" nowadays for different manufacturing goods in international markets and that is the reason it is experiencing a big amount of surpluses in trade from its key trading associates, causing an extensive criticism that China may deliberately manipulate the exchange rate of (RMB) to be considerably underestimated. On July 21, 2005, China made some important changes in exchange rate policy due to the pressure exerted by other countries and the U.S. about trade sanctions 
and China steadily shift to a more flexible exchange rate policy. IMF indicated China's currency largely reflects it's fair value in June 2016 and also some of harshest former critics agree with that assessment. Though, the problem of Chinese Yuan exchange rate remains at the focus of continuing argument over the source of global existing account imbalance since China still continues to run a growing trade surplus. In general, despite there are mixed empirical results, most policymakers believed that depreciation improves a nation's trade balance (Bahmani-Oskooee, 2014). Thus, we are re-assessing the exchange rate and TB relationship in China by using the most recent data. To examine the relationship we used a novel method (the bootstrap Granger full-sample causality test and sub-sample rolling window estimation test).

This study proceeds as follows. In Section 2 we have brief literature review on the exchange rate and TB relationship and about trade balanced elasticity theory. The methodology is explained in section 3. For corresponding data, we have section 4. Section 5 presents the policy implications and empirical results. Section 6 concludes.

\section{Literature Review}

The exchange rate and the TB relationship is historically associated with the trade balanced elasticity theory and it is very well known and we already mentioned above. The elasticity approach to the balance of payments was put forward by Bickerdike (1920), Robinson (1947) and Metzler (1948), which shows when exchange rates depreciate the TB improves. Further Marshall (1923) and Lerner (1944) study the idea that there is a positive impact on TB of devaluation or depreciation or if the demand elasticity absolute value exceeds one for imports and exports. Junz and Rhomberg (1973), followed by Magee (1973), inspect the effect of exchange rate changes on the TB and discover that whenever in exchange rates changes occur, It will take time for producers and consumers fully adjust to that change, which would give rise to J-curve.

In 1990s numbers of empirical studies emerged to examine the exchange rate and TB relationship in different part of the world. While in some studied unidirectional or bidirectional causal relationship was found between exchange rate and TB.(Garcia-Herrero \& Koivu, 2009; Yaya \& Lu, 2012; Xu, 2008), The additional studies which follow the trade balanced elasticity theory research patterns suggest that there is a positive relationship between them in the short-run and a negative relationship in the long-run. Saeed and Hussain (2013), Lencho (2013), Bhattarai and Armah (2013), Kyophilavong et al. (2013) and Matlasedi et al (2015) discover that in case of Pakistan both J-curve and Marshall-Lerner condition effect hold, Ethiopia, Ghana, Laos, South African respectively. However, Jiang (2014) conclude that on the TB, exchange rate change has a positive impact on the long-run case. Hoang (2016), Bahmani-Oskooee and Harvey (2014), Tunaer Vural (2016), Schaling and Kabundi (2014), The short-run exchange rate has a positive impact on TB claimed by Bahmani-Oskooee et al. (2014) and Bahmani-Oskooee et al. (2017), which means J-curve effect exists. However, Shahbaz et al. (2012), Cao-Alvira (2014), and Baek (2013), Narayan (2006), Bahmani-Oskooee and Wang (2006), conclude for the J-curve hypothesis there is not much support found. The long-run currency depreciation improves the TB and Bahmani-Oskooee and Zhang (2014), Igue and Ogunleye (2014), Iqbal et al. (2015), Hsing (2009) and Ogutu (2014) argued about it. Whereas, Wang et al.(2012) and Datta (2014) found there is no significant impact of depreciation on the TB, therefore, the Marshall-Lerner condition is not satisfied. There is also some work that presents TB and exchange rate has no obvious relationship. For example, Wilson and Mclean (2014) reveal only little adjustments in the TB to exchange rate changes both in the long and short-run. Zhang and Sato (2008) reach almost the same conclusion that on China's balance of trade the effect of the exchange rate is still limited. Yue and Zhang (2014) test the causal relationship among Chinese exchange rate with the huge U.S. trade deficit and find that the U.S. trade deficit wouldn't be reduced much by an alteration in the Chinese exchange rate unaccompanied by efforts in regard to the other factors.

This paper will make a little part in the existing literature in the causal relationship between RMB exchange rate and TB by taking time variation into consideration. The former literature considered full-sample causality and general case only, which is liable to give wrong results and conclusions in the presence of parameter instability resulting from structural changes. In the past few decades in the exchange rate and TB, China has faced economic structural changes. The RMB management faced a shift from a de facto USD peg from 1994-2005 to a managed floating rate starting in July 2005 (Ma \& McCauley, 2011). The People's Bank of China announced On 11 August 2015 that it would "proceed further with reform of the RMB exchange rate regime and enhance the RMB exchange rate flexibility," with the stress on making the RMB exchange rate reflect "market supply and demand with reference to a basket of currencies"(Yu et al., 2017). In addition, the Global Financial Crisis (2007-2008) are the nastiest financial crisis considered by many economists since the Great Depression of the 1930s. Maybe these reforms or crise are the reason for structural changes in China. (Balcilar et al., 2010) the dynamic associations among the two series will display uncertainty across different sub-samples in the existence 
of structural changes, We recommended using bootstrap Granger full-sample causality and sub-sample rolling window estimation to re-examine the TB and exchange rate relationship in China. We have formal mathematical methods like pulse impulse response methods (correlation analysis and Granger causality, etc.) but bootstrap rolling-window method is different from this kind of formal methods. Conventional methods are not able to classify sub-sample and full-sample relationships. According to (Balcilar et al., 2013) the empirical studies investigative causality among two-time series might suffer from incorrect results when the underlying full-sample time series have structural changes. This can be addressed if as an alternative of using full-sample data that assume the single causality holds in every time period use the causal relationship among the two series to be time-varying. In this paper, the nature of time-varying also been taken into full consideration, which may exist in the exchange rate and TB causal. The results show that in several sub-periods, the real effective exchange rate has both positive and negative impacts on the TB and in turn, the TB has the same effects on the real effective exchange rate for China. It is inconsistent with trade balanced elasticity theory that an initial currency devaluation is expected to worsen the TB in short-run, before leading to an improvement in the long-run.

\subsection{Trade Balanced Elasticity Theory}

In TB and exchange rate the presence of a theoretical relationship can be seen by the trade balanced elasticity theory (Krueger, 1983). Initially, upon partial equilibrium analysis is founded, in the sense that it considers exchange-rate variations effect in the imports and export market. Secondly, for the foreign import and domestic export good the supply elasticity is perfectly elastic, so that no effect on prices, while having fluctuations in demand volumes. Thirdly, there is no import and export of labor services or movement of capital, so a country's balance of payment is equal to its TB. Fourthly, the demand for import and export commodities is the function of these goods and its substitute products price level assuming that income level is fixed.

The TB, when described in terms of the import-export value, is given by:

$$
B=\frac{x}{E}-M
$$

where $B$ is the TB in foreign currency measurement, $E$ is the exchange rate (domestic currency units per unit of foreign currency), and $x$ is the domestic currency value of exports. While $M$ is the foreign currency value of imports. Take the derivative of $\mathrm{E}$, the above fundamental formula can be changed as

$$
\frac{d B}{d E}=\frac{d\left(\frac{x}{E}\right)}{d E}-\frac{d M}{d E}=-\frac{x}{E^{2}}+\left(\frac{1}{E^{2}}\right)\left(\frac{d x}{d E}\right)-\frac{d M}{d E}
$$

Extract the common factor, Equation (2) becomes

$$
\frac{d B}{d E}=-\frac{x}{E^{2}}\left(1-\frac{\left(\frac{d x}{x}\right)}{\frac{d E}{E}}+\frac{\left(\frac{E M}{x}\right)\left(\frac{d M}{M}\right)}{\frac{d E}{E}}\right)
$$

Now we introduce two definitions; the price elasticity of demand for imports $\eta_{\mathrm{m}}$, the price elasticity of demand for exports $\eta_{\mathrm{x}}$. So the above equation becomes:

$$
\frac{d B}{d E}=-\frac{X}{E^{2}}\left(1-\eta_{x}-\frac{E M}{X} \cdot \eta_{\mathrm{m}}\right)
$$

Assume there is a position of equilibrium in the TB, so

$$
E M=x
$$

Substituting Equation (5) into Equation (4) we obtain:

$$
\frac{d B}{d E}=-\frac{X}{E^{2}}\left(1-\eta_{x}-\eta_{\mathrm{m}}\right)
$$

Equation (6) is called the Marshall-Lerner (ML) condition, which says in TB starting from a position of equilibrium, the TB will improve by a devaluation, that is $d B / d E>0$ only if the home country elasticity of demand for imports and foreign elasticity of demand exports sum is greater than unity; that is, $\eta_{x}+\eta_{m}>1$. A devaluation will lead to a deterioration of the TB if two elasticities sum is less than unity

This can be expected that this devaluation may bring us deteriorating case rather than improvement in the balance of trade led to empirical estimates of the elasticity of demand for imports and exports. It's a general agreement that elasticities, in the long-run are higher than in the short-run, so in that case, the ML conditions may not be satisfied in the short-run but in the medium-long-run it is satisfied. Goldstein and Kahn (1985) determine that, in general, long-run elasticities (greater than two years) are approximately twice as great as short-run elasticities (0-6 months). Moreover, the short-run elasticities fail to sum to unity generally. Whereas the 
long-run elasticities almost each time sum to superior than unity. The possibility that in the small run the ML condition not be satisfied while it normally holds over the long-run leads to the wonder of the J-curve result.

\section{Methodology}

\subsection{Bootstrap Full-sample Causality Test}

The Likelihood Ratio $(L R)$ and Lagrange Multiplier $(L M)$ may not have average asymptotic supplies because structural vicissitudes at all times exist in time sequence and the VAR model (Sims et al., 1990). Modified Wald test, which obtains standard asymptotic supply for the Wald test by approximating an augmented VAR model with I (1) variables was proposed by (Toda \& Yamamoto, 1995). Though, it flops in small and medium examples according to Monte Carlo simulations. Shukur (2000) study the serious values of the residual-based bootstrap method. Several lessons have complete its efficiency without seeing whether the two variables are not cointegrated (Balcilar et al., 2010). Mantalos in 2000 verifies the $R B$ way is particularly outstanding for normal asymptotic tests and for power and size goods in small sample modified $L R$ tests. Therefore, we can use $R B$ based on modified-LR statistics to observe the causal connection concerning exchange rate and TB in China.

We careful the VAR process as follows;

$$
y_{t}=\Phi_{0}+\Phi_{1} y_{t-1}+\cdots+\Phi_{p} y_{t-p}+\varepsilon_{t}, \quad t=1,2, \ldots \cdots
$$

Where $\varepsilon_{t}=\left(\varepsilon_{1 t}, \varepsilon_{2 t}\right)^{\prime}$ is a white noise procedure with zero mean and covariance matrix $\sum$. The optimal lag length $p$ is strong-minded by the Schwarz Evidence Criteria (SIC) in this study. If $y_{t}=\left(T_{t}, R_{t}\right)^{\prime}$ is split into two sub-vectors, $T_{t}$ and $R_{t}$, the above Equation (7) can accordingly be represented as

$$
\left[\begin{array}{l}
T_{t} \\
R_{t}
\end{array}\right]=\left[\begin{array}{l}
\Phi_{10} \\
\Phi_{20}
\end{array}\right]+\left[\begin{array}{ll}
\Phi_{11}(L) & \Phi_{12}(L) \\
\Phi_{21}(L) & \Phi_{22}(L)
\end{array}\right]\left[\begin{array}{l}
T_{t} \\
R_{t}
\end{array}\right]+\left[\begin{array}{l}
\varepsilon_{1 t} \\
\varepsilon_{2 t}
\end{array}\right]
$$

Anywhere $\mathrm{T}$ and $\mathrm{R}$ indicate the first change of trade equilibrium and exchange rate in China respectively. $\Phi_{i j}(L)=\sum_{k=1}^{p+1} \Phi_{i j, k} L^{k}, i, j=1,2$ and $L$ is the lag worker defined $L^{k} x_{t}=x_{t-k}$.

According to the Equation 8 null hypothesis that conversation rate do not Granger reason trade equilibrium is verified by impressive the limit, $\Phi_{12, k}=0$ for $k=1,2, \ldots \ldots, p$. Likewise, the null hypothesis that trade equilibrium do not Granger reason conversation rate is tested by impressive the constraint, $\Phi_{21, k}=0$ for $k=1,2, \ldots \ldots, p$. The full-sample connection tests in this editorial are trusted upon $R B$ based $p$-values and modified-LR statistics. If the first null hypothesis $\Phi_{12, k}=0$ for $k=1,2, \ldots \ldots, p$ is disallowed, then there is an important connection successively from exchange rate to TB in China. In result the conversation rate can expect actions in trade equilibrium. This offers indication for China that reduction in argument rate would likely increase TB performance. Similarly, if the second null hypothesis, $\Phi_{21, k}=0$ for $k=1,2, \ldots \ldots, p$ is disallowed, then the discussion rate is caused by actions in TB.

\subsection{Parameter Stability Test}

The full model connection exams typically adopt that the parameters of the VAR model used in testing are continuous over time, and therefore a single causality holds in every time period. Though, full-sample data display structural changes, the hypothesis are maybe despoiled. It shows that the outcomes resulting from the full-sample causality tests might become unacceptable and there would be unpredictability in causal links between series (Ozdemir et al., 2013). Granger in 1996 reported a most interesting issue which is faced in recent experiential research, the issue of parameter non-constancy. As outcome, tests for short-run and long-run parameter constancy should be shown in this paper.

Andrews and Ploberger in 1994 investigated short-run parameters stability. However, it is famous that when the important variables in levels are co-integrated, the VAR model in the first changes would be miss-specified except it permits for error-correction. Therefore, it is essential to test for co-integration and parameter constancy of the long-run connection. In this work we utilize the modified ordinary least rectangles (FM-OLS) estimator of Phillips and Hansen in 1990 to estimation the limits of co-integration reversions and employ the $L_{c}$ test proposed by Hansen (1992) to checked the stability of long-run limitations. Balcilar et al. in 2010 point out the $L_{c}$ test also helps as a test of co-integration when the original series are integrated of the first order i.e, $I(1)$.

The Sup-F, Mean-F, and Exp-F tests are designed from the order of $L R$ data those payments the constancy of parameters besides the alternative of a single structural break at an unknown time. Furthermore, since these tests show unusual asymptotic supplies, Andrews and Ploberger (1994) reported critical values and $p$-values by means of the parametric bootstrap process. The 15 percent trimming from both ends of the model is required for the Sup-F, Mean-F, and Exp-F tests. Consequently, these tests are applied to the segment of the sample in $(0.15$, 
0.85). With admiration to the $L_{c}$ tests in the current article, they are calculated distinctly for equations and VAR system by the FM-OLS estimator.

\subsection{Sub-Sample Rolling-Window Causality Test}

To overwhelm the factor non-constancy and evade pre-test bias, we use rolling-window bootstrap estimation (Balcilar et al., 2010). First, the essential association among variables rolling window method can change over time. Secondly, rolling approximation can detect unpredictability through diverse sub-samples due to structural change, and the rolling-window estimation captures this process.

A fixed-size subsample from the beginning to the end of the full sample is the base of the rolling window method. Precisely, given a rolling window with a fixed size, including observation $l$ the full sample is changed to a structure of $T-l$ sub-samples, that is, $\tau-l+1, \tau-l, \ldots, T$ for $\tau=l, l+1, \ldots, T$. The RB based altered LR causality test is then connected to each sub-test, rather than evaluating a solitary causality test for complete sample. Conceivable time varieties in the causal connections between conversion scale and exchange adjust are instinctively distinguished by computing the bootstrap p-estimations of watched LR-measurement moving through T-1 sub-tests. Likewise, the extent of the impact of swapping scale on exchange adjust and additionally that of exchange adjust on conversion standard is additionally evaluated in this investigation. The effect of conversion scale on exchange adjust is characterized as the normal of the whole bootstrap estimates deriving from the formula $N_{b}^{-1} \sum_{k-1}^{p} \widehat{\Phi}_{21, k}^{*}$, with $N_{b}$ is bootstrap number of repetitions; in similar way, the change of TB effect on exchange rate can be get from the formula $N_{b}^{-1} \sum_{k-1}^{p} \widehat{\Phi}_{21, k}^{*}$. In Equation (8) $\widehat{\Phi}_{21, k}^{*}$ and $\widehat{\Phi}_{12, k}^{*}$ both are bootstrap estimates from the VAR models. The 90-percent confidence intervals are also computed, where the lower and upper limits equal fifth and ninety-fifth quantiles of each of the $\widehat{\Phi}_{21, k}^{*}$ and $\widehat{\Phi}_{12, k}^{*}$, respectively.

In the rolling-window estimation there are two conflicting objectives- the representativeness of the model and accuracy of the parameter estimates in sub-sample period. The Window size controls the amount of observations and it is precision of estimations. Big window size can increase estimates accuracy but can decrease the representativeness in the existence of heterogeneity. Small window size might increase representativeness but decrease accuracy on the other hand. Therefore, to balance the trade-off between accuracy and representativeness we need to choose an appropriate window size.

In 2005 Pesaran and Timmerman determine that ideal window size relies on persistence and size of the break by measuring the window size taking structural change in consideration and which is according to square root mean square error. Furthermore significantly, 20 is the least limit of window size when there are frequent breaks based, according to Monte Carlo simulations. Taking it and the two conflicting demands of the previous paragraph together, we choose a window size of 24 months (this excludes the observations required for lags and, hence, is the actual number of observations in the VAR). Big window size is required to guarantee the accuracy of parameter estimates, however a huge window size might raise the risk of including some of these multiple shifts in the window sample claims for a smaller window size. As for the issue of inaccurate estimates as a result of the selected small window size, it can be addressed by the bootstrap technique employed in the rolling estimation for better precision.

\section{Data}

The variables in this study are trade balance (TB) and real effective exchange rate (REER). We use the monthly data covering the period 2005:8 to 2016:7 because the RMB exchange rate has been flexible 2005 reform. The effective exchange rate is a measure of whether or not the currency is appreciating or depreciating against a basket of foreign currencies. While effective exchange provides a reasonable measure of changes in a countries competitive position for periods of several months. In adjustment to get a better abstraction of changes in countries aggressive we would need to use a real exchange rate index (Datta, 2014).

Figure 1 indicates that the Real Effective Exchange Rate (REER) of RMB and trade balance (TB) has several significant changes. First, in the period 2005:08-2008:07, RMB appreciated quite stably. RMB exchange rate has been getting more flexible, during this period since China undertook RMB exchange rate reform on July 21, 2005. On that date, the PBOC announced that the changes were made "with a view to establish and improve the socialist market economic system in China, enable the market to fully play its role in resource allocation as well as to put in place and further strengthen the managed floating exchange rate regime based on market supply and demand". It then allowed a one-time appreciation in the RMB and said it was starting to peg the RMB to a basket of currencies, indicating a more flexible RMB exchange rate with its value based more on market mechanism. As a big developing country, China always tries to integrate the world economy and as one part of the world financial system (Bai, 2012). In this time, TB clearly shows an upward pattern with certain ups and 
down in between. The second significant change appeared in 2008:07-2009:03. Because of the global financial crisis, U.S., Japan and other Europe countries' economic status got worse and their currencies are depreciated relative to the RMB. REER appreciated quite rapidly. Then in 2009:03-2009:11, the RMB virtually returned to a dollar peg to halt appreciation because of the effects of the global economic crisis on China's exporters (Morrison \& Labonte, 2013). The RMB exchange rate devaluates sharply. China as an export country which highly dependent on the international market, the global financial crisis has also affected China's economic and trade market, leading a sharp decline in TB (Bai, 2012). In the period 2010-2015, RMB resumed appreciation, and especially in 2014:05-2015:03, the process of internationalization of RMB accelerates the appreciation of REER. In this time, there is a sharp rise in TB. Then the downward trend of REER repeates since the PBOC intervened in the foreign exchange market in August 2015. Meanwhile, TB remains at high levels with many "ups and downs". We find that the REER and TB seem to change in the same direction. However, between REER and TB there may be movements in the contrary direction in some periods. Generally, the REER and TB relationship is complex.

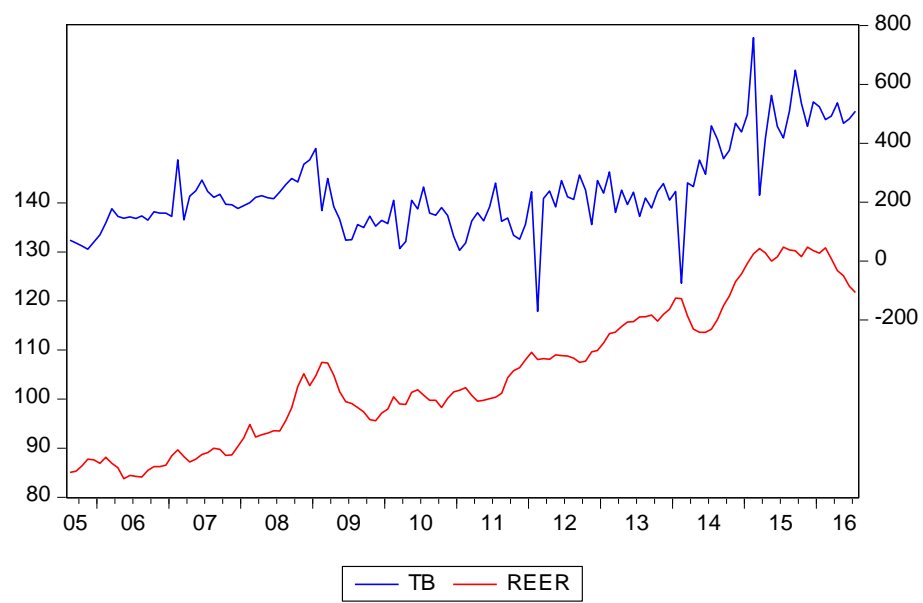

Figure 1. Time plots of Real Effective Exchange Rate (REER) and Trade Balance(TB)

\section{Empirical Results}

It is really important to check for the stationery of the variables being used, to ensure that our regression results are not spurious. In adjustment to do this, to analysis the adherence of the time alternation we use aggrandized Dickey-Fuller analysis (ADF analysis, Dickey and Fuller, 1981). In the ADF analysis we found that the absolute able exchange rate and TB antithesis are not stationary at not stationary at level but after 1st difference become stationary. Which shows that both of them are first order cohesive, i.e., I (1), and a co-integration analysis would be executed to check is the VAR models in first differences are miss specified by neglecting an error-correction term. Since we are more absorbed in abstraction the causal accord among the REER and TB, bivariate VAR models containing the first-differenced log-levels of both the REER and TB are then complete, bivariate VAR models containing the first-differenced log-levels of both the REER and TB are then constructed, as in Equation (8). Upon examination, the optimal lag-lengths based on Akaike advice archetype (AIC) of REER and TB are 3. in table 1 the full-sample causality results after-effects based on the RB-based modified-LR agent tests are appear. By the bootstrap p-values, REER doesn't Granger-cause TB, and TB does Granger cause REER. This award is unstable with some of the absolute abstract (Narayan, 2006; Jiang, 2014) and argues that the RMB exchange rate has no long-run relationship with China's TB.

Table 1. Full-sample Granger causality tests

\begin{tabular}{lcccc}
\hline Tests & $\mathrm{H}_{0}$ : REER does not Granger cause TB & \multicolumn{2}{c}{$\mathrm{H}_{0}$ : TB does not Granger cause REER } \\
\hline & Statistics & $p$-values & Statistics & $p$-values \\
Bootstrap $L R$ Test & 4.210 & 0.276 & 4.957 & 0.160 \\
\hline
\end{tabular}

Note. Eviews software is used for these tests.

Though, there is an evasion supposition in the preceding works that structural fluctuations don't occur and there is only a single causal association across the whole sample period (Balcilar et al., 2013). In the existence of structural variations, the parameters in the above VAR models molded by the two variables in their first 
differences will shift with time. The causal connection between the REER and TB in China will appropriately be insecure. Thusly, the full-example causality tests with presumptions of parameter steadiness and a solitary causal relationship over the entire specimen time frame are never again solid, and the following outcomes turn out to be futile (Zeileis et al., 2005). Therefore, this paper continues to test for parameter solidness and to decide if auxiliary changes exist. As specified some time recently, we utilize the Sup-F, Mean-F and Exp-F tests created by Andrews (1993) and Andrews and Ploberger (1994) to examine the temporal constancy of parameters in the above VAR models formed by two variables in their first differences. The $L_{c}$ test of Hanson (2002) and Nyblom (1989) utilized here to test for the majority of the parameters in the general VAR framework. The relating comes about are accounted for in Table 2. The Sup-F tests under the invalid theory of parameter steadiness against a one-time sharp move in parameters are accounted for in the principal push. The outcomes recommend that a one-time sharp move exists in the genuine viable conversion scale at the $1 \%$ level. The Mean-F and Exp-F tests under the invalid speculation that parameters take after a martingale procedure against the likelihood that the parameters may develop step by step are accounted for in the second and third columns, individually. The outcomes propose that condition from the REER may advance step by step with time. Despite the fact that it isn't characteristic of the parameters' consistency in the general VAR models assessed using the full-specimen information for China from the $L_{c}$ insights test, huge confirmation exists that the parameters of the evaluated VAR demonstrate utilizing full-example information indicate short-run shakiness.

Table 2. Short-run parameter stability tests

\begin{tabular}{lllllll}
\hline & \multicolumn{2}{c}{ TB Equation } & \multicolumn{2}{c}{ REER Equation } & \multicolumn{2}{c}{ VAR System } \\
\cline { 2 - 6 } & Statistics & $p$-value & Statistics & $p$-value & Statistics & $p$-value \\
\hline Sup $-F$ & 18.387 & 0.148 & $52.409^{* * *}$ & 0.000 & 20.322 & 0.701 \\
Mean-F & 8.541 & 0.233 & $12.886^{* *}$ & 0.025 & 13.952 & 0.457 \\
Exp-F & 6.445 & 0.129 & $21.693^{* * *}$ & 0.000 & 8.436 & 0.507 \\
$L_{c}{ }^{b}$ & & & & 2.773 & 0.199 \\
\hline
\end{tabular}

Note. The p-values are calculated by using 10,000 bootstrap repetitions. ** and $* * *$ denote significance at the $5 \%$ and $1 \%$ level, respectively. Hansen-Nyblom parameter stability test for all parameters in the VAR jointly. These tests are used by R software.

The two factors, the REER and TB, are both I (1) forms, as demonstrated by the aftereffects of the ADF unit root test. Accordingly, the FM-OLS estimator is utilized to assess co-integration. The Sup-F and test are utilized to test the parameter solidness of the long-run relationship. The related outcomes are displayed in Table 3. As indicated by the bootstrap p-values in the second column, the measurements dismiss the invalid theory of co-integration at $1 \%$. In the meantime, the Sup-F insights dismiss the invalid theory of parameter steadiness at $1 \%$. In spite of the fact that the continuous moving of parameters in the co-integration condition can't be recognized from the Mean-F and Exp-F tests, noteworthy confirmation exists of a one-time move over the long haul relationship subsequently, no dependable co-integration amongst REER and TB in China can be gotten from the from the $L_{c}$ and Sup-F tests.

Table 3. Long-run parameter stability tests

\begin{tabular}{lllll}
\hline & Sup- $\boldsymbol{F}$ & Mean- $\boldsymbol{F}$ & $\mathbf{E x p}-\boldsymbol{F}$ & $\boldsymbol{L}_{\boldsymbol{c}}$ \\
\hline TB $=\boldsymbol{\alpha}+\boldsymbol{\beta} *$ REER & $244.772^{* * *}$ & 145.166 & 117.835 & $11.403^{* * *}$ \\
Bootstrap $\boldsymbol{p}$-value & 0.000 & 1.000 & 1.000 & 0.005 \\
\hline
\end{tabular}

Note. p-values are calculated by using 10,000 bootstrap repetitions.

The numbers in parentheses indicate the lag order selected based on the recursive t-statistic, as suggested by Perron (1989).

*** indicates significance at the $1 \%$ level.

Depending upon the above parameter solidness tests, we can presume that models assessed utilizing full-specimen information are insecure in view of the nearness of basic changes. This implies the consequence of nonappearance of any full-specimen causality between the REER and TB isn't solid. To consider basic changes, we utilize moving windows estimation to test the causal connection amongst REER and TB; not at all like the full-example causality test, this approach tests the causal connection among two factors all the more precisely for the cause of time-shifting crosswise over various sub-tests. In the sub-test causality trial of the moving window, we utilize the RB bootstrap-based adjusted LR causality test to check the causal connection amongst REER and TB. The invalid speculation of the tests demonstrate that REER does not Granger cause TB and the other way around. The bootstrap p-estimations of LR-insights can be evaluated from the VAR models in Equation (8) 
utilizing the moving sub-test information including two-year perceptions. All the rolling assessments for each sub-test are plotted in Figures 2 to 5. In the wake of trimming two-year perceptions from the earliest starting point of the full sample, these rolling estimates move from 2007:08 to 2016:07.

In Figure 2 we can see that the null hypothesis that REER doesn't Granger-cause TB is rejected at the $10 \%$ significance level in some sub-sample periods, containing 2009:03-2010:04, 2012:09-2012:12 and 2014:10-2015:02. Figure 3 shows that in 2009:03-2010:04 and 2014:10-2015:02, REER has a negative impact on TB, while in 2012:09-2012:12, REER put a positive effect on TB. From Figure 1 we can see, RMB has been appreciated gradually since 2005 and has risen sharply in the period 2008:07-2009:02 because of the 2008 financial crisis. As a result of the lag exchange rate effect on TB, the appreciation in RMB has a negative impact on TB in 2009:03-2010:04 (Junz \& Rhomberg, 1973; Magee, 1973). During that time, as the global economic downturn continued to weaken foreign demand, both exports and imports declined by record-high percentage points. China's TB drops sharply in several months. According to (Morrison \& Labonte, 2013) the RMB virtually returned to a dollar peg to halt appreciation because of the influence of global economic crisis on China's exporters. It resumed RMB appreciation in June 2010 (Morrison \& Labonte, 2013). In order to curb the decline in exports, through (2011-2015) the 12th five-year plan period China makes struggles to keep its present competitive edge in exports, foster new benefits centering on technology, branding, quality and services at a quicker speed, promote industrial upgrading and transformation and the competitiveness and added value of enterprises and products. As a result of a greater reduction in imports than in exports, in 2012:09-2012:12, REER appreciates and has a positive impact on TB. From 2014:05, REER rises sharply because of the process of internationalization of RMB. Until 2014:10-2015:02 period, REER has a negative impact on TB, which means the appreciation of the REER puts downward pressure on TB. Though, in further periods, REER has no meaningful impact on TB. The bootstrap sub-sample rolling estimates show that the REER has an effect on TB both negative and positive shown in Figure 3.

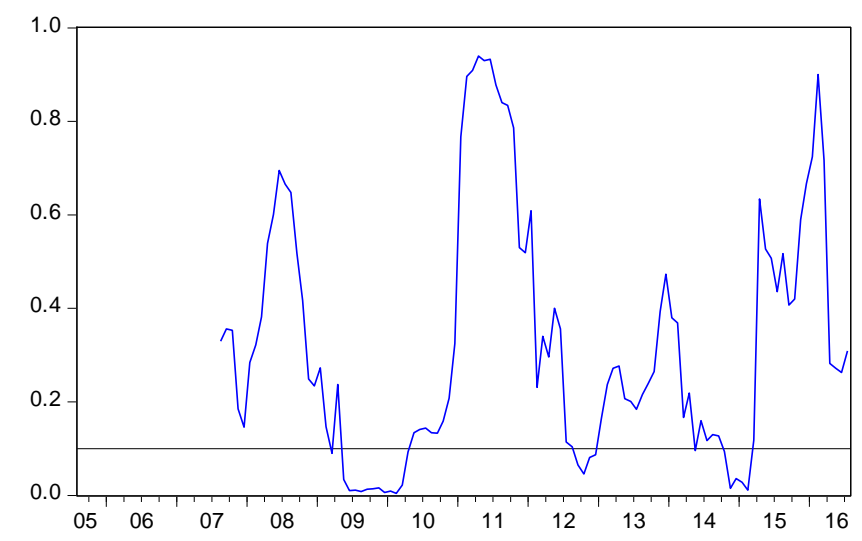

Figure 2. Bootstrap p-value of rolling test statistic testing the null that REER does not Granger cause TB

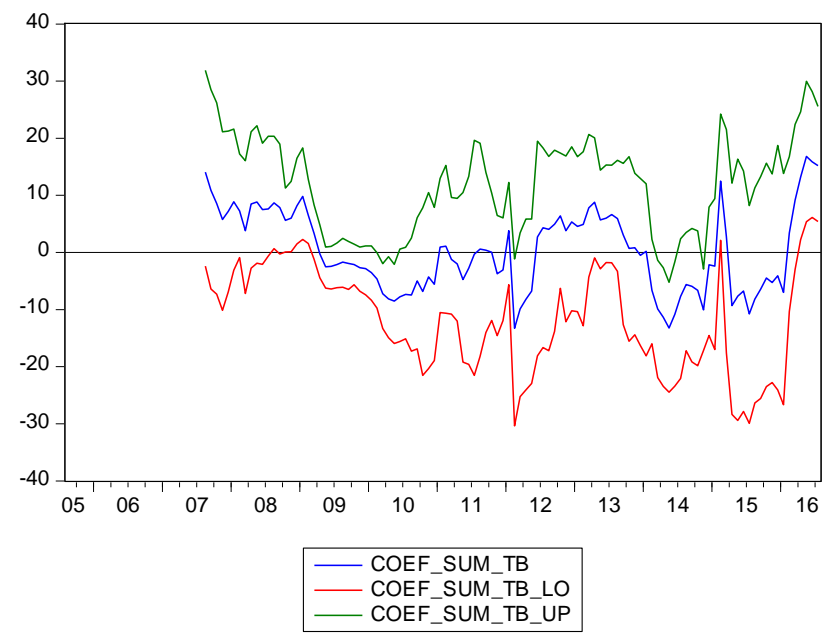

Figure 3. Bootstrap estimates of the sum of the rolling window coefficients for the impact of REE 
The Figure 4 shows the rolling bootstrap $p$-values of the $L R$-statistic with the null hypothesis that TB doesn't Granger-cause REER. The rolling estimates of the magnitude of the effect that TB has on REER can be seen in Faigure 5. From figure 4, we can see clearly that the null hypothesis is overruled significantly in 2014:03-2016:03, and the length of time is long. That shows TB has a strong and long effect on REER as compared to the REER effects on TB. From Figure 5 shows that TB has only positive effects on REER. The conclusions can be get from Figure 4 and Figure 5 in summation. Firstly, TB has a strong and long effect on REER. Secondly, there is only positive effect from TB to REER. In recent years, the Chinese government has adopted a further flexible exchange rate system with the RMB value based more on mechanism of market. As the RMB has not been made fully convertible and policymakers have been tightening capital controls, as well as the bank began easing local interest rates to counteract a slowing economy in 2014, the impact of capital inflows on exchange rate is reduced. The TB influences REER through its effect on the demand and supply for foreign-exchange. Chinese trade surplus makes relatively more demand for RMB, which improves the value of Yuan in the world market.

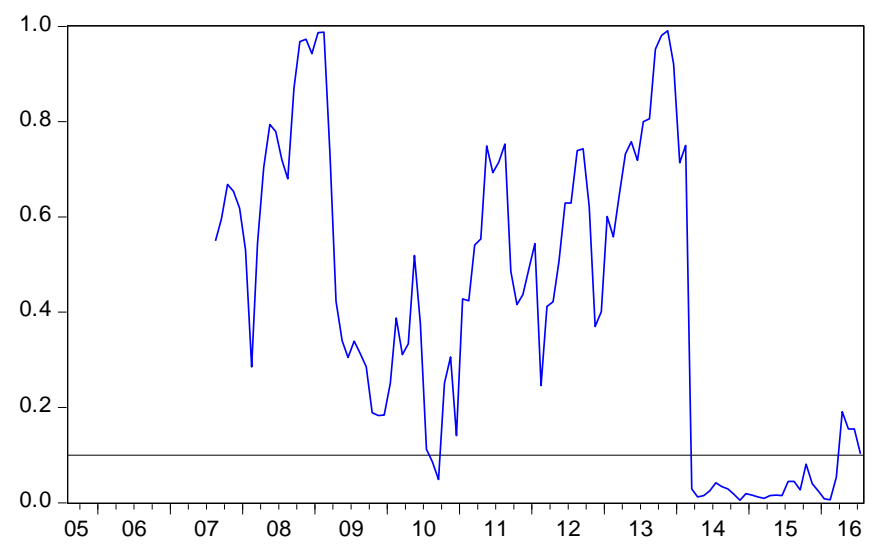

Figure 4. Bootstrap p-value of rolling test statistic testing the null that TB does not Granger cause REER

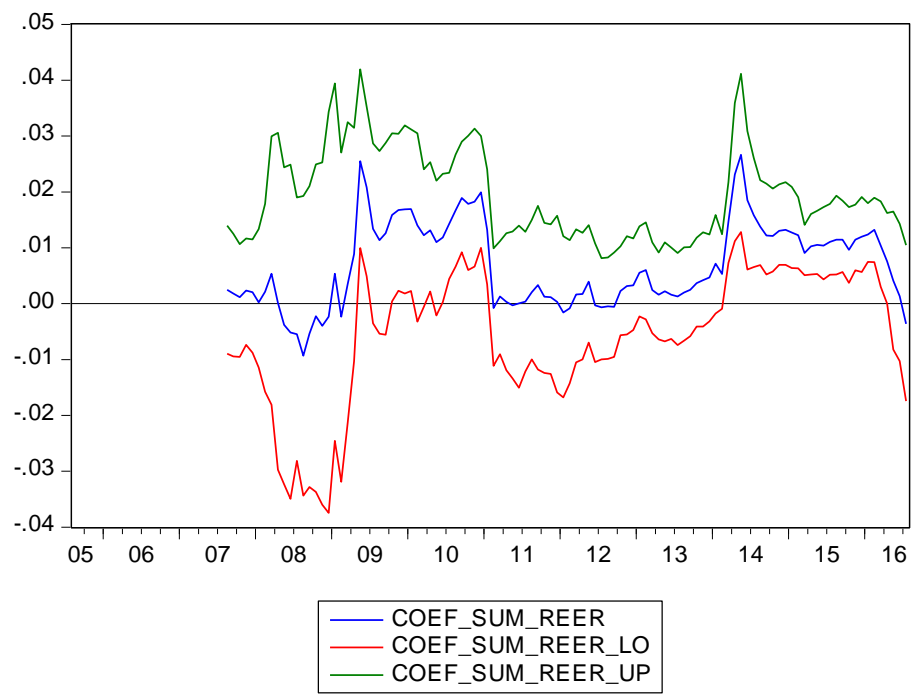

Figure 5. Bootstrap estimates of the sum of the rolling window coefficients for the impact of TB on REER

In this paper, the bootstrap sub-sample rolling window estimation and Granger full-sample causality test provides supplementary vision into the vibrant association between REER and TB in China. The relationship between TB and exchange rate in China is not always steady with the view that an actual currency depreciation rallies TB in the long-run, while worsens a country's TB before leading to an improvement in the short-run(Marshall, 1923; Lerner, 1944; Magee, 1973). It means the Chinese exchange rate and TB relationship doesn't back the theory of trade balanced elasticity.

"In China the relationship between TB and exchange rate is not stable over time and even showed a short-term 
deviation from the positive link. However, it is actually very suitable for China, it's because in the past few decades China has experienced economic restructuring and structural changes in exchange rate policy. In July 2005, China introduced a narrow trading band and made a move toward a liberalization of its currency policy. Over the past decade, the government of China has gradually allowed the trading band to widen, starting at $+/-0.3 \%$ and finally reaching $+/-2 \%$ by March 2014. China took a step further in August 2015 by allowing its currency to devalue outside of the previous trading band. The global financial crisis in 2008 and 2009 also had an impact on the relationship between exchange rate and TB. As a result, the relationship between exchange rate and TB should not be considered simply in terms of the positive or negative correlation between them. We should utilize more scientific methods and also consider the specific economic backgrounds to find out an accurate view of the complicated relationship for China".

\section{Conclusions}

This study uses sub-sample rolling window causality estimation and the bootstrap full-sample Granger causality test to examines the TB and REER causal relationship in China. By the full-sample Granger causality test we found that REER and TB has no long-run relationship. However, parameter stability test shows that REER and TB short-run relationships are unsteady by taking the full-sample data structural changes into consideration. More on by using another bootstrap sub-sample approach we found there exist bidirectional causal relationships. It is not consistent with Marshal-Lerner condition that currency depreciation should put forth a promising impact on the nation's TB. Our results are consistent with the J-curve effect when the exchange rate rises or falls sharply, which means that hat currency devaluation is expected to worsen in short-run TB, before prominent to a progress in the long-run in some unusual times, such as the global economic crisis and the process of accelerating the internationalization of RMB in 2014. Although in China the exchange rate and trade balance relationship is not steady over the time and even shows some deviations in short-run, actually it fits very well with the fact that China has faced structural changes and economic transitions in the exchange rate policy. In normal economic circumstances, the REER have no impact on TB if the REER does not change much in the short term. This provides Chinese government some implications. Firstly, the exchange rate effect is still limited on China's TB, China's monetary authority has both balance of trade and exchange rate constancy as its policy goals. Second, the TB would not reduce much by the change in the Chinese exchange rate unaccompanied by efforts in regard to the other factors. The exchange rate and TB relationship shouldn't be considered just in terms of the negative or positive correlation between ER and TB. There is a need to consider the precise economic backgrounds and utilize more scientific methods to acquire a correct view of the complex relationship for China. The words of the critics who argue that RMB was extremely underestimated, which in turn allows China to got unfair trade rewards do not make sense.

\section{References}

Andrews, D. W. K. (1993). Tests for parameter instability and structural change with unknown change point. Econometrica, 61, 821-856. https://doi.org/10.2307/2951764

Andrews, D. W. K., \& Ploberger, W. (1994). Optimal tests when a nuisance parameter is present only under the alternative. Econometrica, 62, 1383-1414. https://doi.org/10.2307/2951753

Baek, J. (2013). Does the exchange rate matter to bilateral trade between Korea and Japan? Evidence from commodity trade data. Economic Modeling, 30, 856-862. https://doi.org/10.1016/j.econmod.2012.11.020

Bahmani-Oskooee, M., \& Harvey, H. (2014). U.S.-Singapore commodity trade and the J-curve. Asian Economic and Financial Review, 4(10), 1473-1484.

Bahmani-Oskooee, M., Harvey, H., \& Hegerty, S. W. (2014). Brazil-US Commodity Trade and the J-Curve. Applied Economics, 46, 1-13. https://doi.org/10.1080/00036846.2013.824548

Bahmani-Oskooee, M., \& Wang, Y. (2006). The J-curve: China versus her trading partners. Bulletin of Economic Research, 58(4), 307-378. https://doi.org/10.1111/j.1467-8586.2006.00247.x

Bahmani-Oskooee, M., \& Wang, Y. (2008). The J-curve: Evidence from commodity trade between US and China. Applied Economics, 40, 2735-2747. https://doi.org/10.1080/00036840600970328

Bahmani-Oskooee, M., Xu, J., \& Saha, S. (2017). Commodity trade between the U. S. and Korea and the J-curve effect. New Zealand Economic Papers, 51(1), 1-14. https://doi.org/10.1080/00779954.2015.1095786

Bahmani-Oskooee, M., \& Zhang, R. (2014). Is there J-curve effect in the commodity trade between Korea rest of the world? Economic Change and Restructuring, 47, 227-250. https://doi.org/10.1007/s10644-013-9148-5

Bai, L. (2012). Effects of global financial crisis on Chinese export: A gravity model study. Sweden: Jonkoping 
University.

Balcilar, M., Ozdemir, Z. A., \& Arslanturk, Y. (2010). Economic growth and energy consumption causal nexus viewed through a bootstrap rolling window. Energy Economics, 32(6), 1398-1410. https://doi.org/10.1016/j.eneco.2010.05.015

Balcilar, M., \& Ozdemir, Z. A. (2013). The export-output growth nexus in Japan: A bootstrap rolling window approach. Empirical Economics, 44, 639-660. https://doi.org/10.1007/s00181-012-0562-8

Bhattarai, K. R., \& Armah, M. (2013). The effects of exchange rate on the trade balance in Ghana: Evidence from co-integration analysis. African Journal of Business Management, 7(14), 1126-1143.

Bickerdike, C. F. (1920). The instability of foreign exchanges. The Economic Journal, 30, 118-122. https://doi.org/10.2307/2223208

Cao-Alvira, J. (2014). Real exchange rate volatility on the short- and long-run trade dynamics in Colombia. The International Trade Journal, 28(1), 45-64. https://doi.org/10.1080/08853908.2013.820654

Datta, K. (2014). Relationship between currency depreciation and trade balance in India-An Econometric Study. Journal of Finance and Economics, 2(3), 83-89. https://doi.org/10.12691/jfe-2-3-5

Dickey, D. A., \& Fuller, W. A. (1981). Likelihood Ratio Statistics for Autoregressive Time Series with a Unit Root. Econometrica, 49(4), 1057-1072. https://doi.org/10.2307/1912517

Garcia-Herrero, A., \& Koivu, T. (2009). China's Exchange Rate Policy and Asian Trade. BIS Working Papers, No. 282. https://doi.org/10.2139/ssrn.1458287

Goldstein, M., \& Kahn, M. S. (1985). Income and price effects in foreign trade. Handbook of International Economics, 2, 1041-1105. https://doi.org/10.1016/S1573-4404(85)02011-1

Granger, C. W. J. (1996). Can we improve the perceived quality of economic forecasts? Journal of Applied Econometrics, 11 , 455-473. https://doi.org/10.1002/(SICI)1099-1255(199609)11:5<455::AID-JAE408>3.0.CO;2-E

Hansen, B. E. (1992). Tests for parameter instability in regressions with I(1) processes. Journal of Business and Economic Statistics, 10, 321-336.

Hoang, L. H. (2016). The role of exchange rate in supporting trade balance in Vietnam. Working Paper No. HEIDWP16, State Bank of Vietnam, Vietnam.

Hsing, Y. (2009). Test of the J-curve for the DR-CAFTA countries and policy implications. Research in International Business and Finance, 23(3), 293-301. https://doi.org/10.1016/j.ribaf.2008.11.005

Igue, N. N., \& Ogunleye, T. S. (2014). Impact of real exchange rate on trade balance in Nigeria. African Development Review, 26(2), 347-358. https://doi.org/10.1111/1467-8268.12086

Iqbal, J., Nosheen, M., Tariq, R., \& Manan1, S. (2015). Testing for Marshall-Lerner Condition: bilateral trade between Pakistan and its major trading partners. Forman Journal of Economic Studies, 11, 1-14.

Jiang, W. H. (2014). The Effect of RMB Exchange Rate Volatility on Import and Export Trade in China. International Journal of Academic Research in Business and Social Sciences, 4(1), 615-625.

Junz, H. B., \& Rhomberg, R. R. (1973). Price competitiveness in export trade among industrial countries. American Economic Review, 63, 412-418.

Koray, F., \& McMillin, W. D. (1999). Monetary shocks, the exchange rate, and the trade balance. Journal of International Money and Finance, 18, 925-940. https://doi.org/10.1016/S0261-5606(99)00031-5

Krueger, A. O. (1983). Exchange rate determination. Cambridge: Cambridge University press.

Kwan, A. C. C., \& Kwok, B. (1995). Exogeneity and the export-led growth hypothesis: The case of China. Southern Economic Journal, 61(4), 1158-1166. https://doi.org/10.2307/1060747

Kyophilavong, P., Shahbaz, M., \& Uddin, G. S. (2013). Does J-curve phenomenon exist in case of Laos? An ARDL approach. Economic Modelling, 35, 833-839. https://doi.org/10.1016/j.econmod.2013.08.014

Lencho, B. D. (2013). The effect of exchange rate movement on trade balance in Ethiopia. Tokyo: The University of Tokyo.

Lerner, A. P. (1944). The economics of control: Principles of welfare Economics. The Macmillian Company, London: Macmillan. 
Liew, K. S., Lim, K. P., \& Hussain, H. (2000). Exchange rate and trade balance relationship: The experience of ASEAN countries. Journal of Management Sciences, 3, 15-18.

Ma, G., \& McCauley, R. N. (2011). The evolving renminbi regime and implications for Asian currency stability. Journal of the Japanese and International Economies, 25(1), 23-38. https://doi.org/10.1016/j.jjie.2010.09.002

Magee, S. P. (1973). Currency contracts, pass through and devaluation. Brooking Papers on Economic Activity, 1, 303-325. https://doi.org/10.2307/2534091

Mantalos, P., \& Shukur, G. (1998). Size and power of the error correction model cointegration test: A bootstrap approach. Oxford Bulletin of Economics and Statistics, 60, 249-255. https://doi.org/10.1111/1468-0084.00097

Mantalos, P. (2000). A graphical investigation of the size and power of the granger-causality tests in integrated-cointegrated VAR systems. Studies in Non-Linear Dynamics and Econometrics, 4, 17-33. https://doi.org/10.1162/108118200569162

Marshall, A (1923). Money, Credit and Commerce, The Macmillan Company, London: Macmillan.

Matlasedi, T., Ilorah, R., \& Zhanje, S. (2015). The impact of the real effective exchange rate on South Africa's trade balance. Paper presented at the biennial conference of the Economic Society of South Africa, University of Cape Town.

Metzler, L (1948). A Survey of Contemporary Economics. Blakiston Company. American Economic Association, 321-345.

Morrison, W. M., \& Labonte, M. (2013). China's Currency Policy: An Analysis of the Economic Issues. Congressional Research Service.

Narayan, P. K. (2006). Examining the relationship between trade balance and exchange rate: The case of China's Trade with the USA. Applied Economics Letters, 13, 507-510. https://doi.org/10.1080/13504850500400488

Nyblom, J. (1989). Testing for the constancy of parameters over time. Journal of the American Statistical Associatio, 84, 223-230. https://doi.org/10.1080/01621459.1989.10478759

Ogutu, G. O. (2014). Effects of the real exchange rate on the trade balance in Kenya. Research Paper, International Institute of Social Studies, Kenya.

Pesaran, M. H., \& Timmermann, A. (2005). Small sample properties of forecasts from autoregressive models $\begin{array}{llllll}\text { under structural breaks. Journal of Econometrics, } & 129, & 183-217 .\end{array}$ https://doi.org/10.1016/j.jeconom.2004.09.007

Petrovic, P., \& Gligoric, M. (2010). Exchange rate and trade balance: J-curve effect. Paneconomicus, 1, 23-41. https://doi.org/10.2298/PAN1001023P

Qiao, H. (2007). Exchange rates and trade balances under the dollar standard. Journal of Policy Modeling, 29, 765-782. https://doi.org/10.1016/j.jpolmod.2007.06.011

Robinson, J. (1947). Essays in the Theory of Employment (2nd ed., pp. 33-37). United Kingdom: Basil Blackwell.

Saeed, M. B., \& Hussain, I. (2013). Real exchange rate and trade balance of Pakistan: An empirical analysis. Jinnah Business Review, 1(1), 44-51.

Schaling, E., \& Kabundi, A. (2014). The exchange rate, the trade balance and the J-curve effect in South African. South African Journal of Economic and Management Sciences, 5, 601-608. https://doi.org/10.4102/sajems.v17i5.727

Sims, C. A., Stock, J. H., \& Watson, M. W (1990). Inference in linear time series with some unit roots. Econometrica, 58(1), 113-144. https://doi.org/10.2307/2938337

Shukur, G., Mantalos, P (2000). 'A simple investigation of the Granger-causality test in integrated-cointegrated VAR Systems', Journal of Applied Statistics 27: 1021-1031. https://doi.org/10.1080/02664760050173346

Shahbaz, M., Jalil, A., \& Islam, F. (2012). Real Exchange Rate Changes and the Trade Balance: The Evidence from Pakistan. The International Trade Journal, 26, 139-153. https://doi.org/10.1080/08853908.2012.657588

Toda, H. Y., \& Phillips, P. C. B. (1994). Vector autoregression and causality: A theoretical overview and 
simulation study. Econometric Reviews, 13, 259-285. https://doi.org/10.1080/07474939408800286

Toda, H. Y., \& Yamamoto, T. (1995). Statistical inference in vector autoregressions with possibly integrated processes. Journal of Econometrics, 66, 225-250. https://doi.org/10.1016/0304-4076(94)01616-8

Tunaer, V. B. M. (2016). Effect of Real Exchange Rate on Trade Balance: Commodity Level Evidence from Turkish Bilateral Trade Data. Procedia Economics and Finance, 38, 499-507. https://doi.org/10.1016/S2212-5671(16)30221-0

Wang, C. H., Lin, C. H. A., \& Yang, C. H. (2012). Short-run and long-run effects of exchange rate change on trade balance: Evidence from China and its trading partners. Japan and the World Economy, 24, 266-273. https://doi.org/10.1016/j.japwor.2012.07.001

Wilson, S. A., \& Mclean, E. (2014). Understanding the impact of exchange rate adjustment on the Trade balance of selected Caribbean Countries. Working Paper, Bank of Jamaica.

Xing, Y. Q. (2012). Processing trade, exchange rates and China's bilateral trade balances. Journal of Asian Economics, 23, 540-547. https://doi.org/10.1016/j.asieco.2012.06.001

$\mathrm{Xu}$, Z. (2008). China's exchange rate policy and its trade balance with the US. Review of Development Economics, 12(4), 714-727. https://doi.org/10.1111/j.1467-9361.2008.00397.x

Yaya, M. E., \& Lu, X. X (2012). The Short-Run Relationship between Real Effective Exchange Rate and Balance of Trade in China. International Journal of Applied Economics, 9(1), 15-27.

Yi, G. (2013). RMB exchange rate and trade balance. Business Horizons, 56, 421-432. https://doi.org/10.1016/j.bushor.2013.04.001

Yu, Y. D., Zhang, B., \& Zhang, M. (2017). Renminbi Exchange Rate: Peg to A Wide Band Currency Basket. China \& World Economy, 25(1), 58-70. https://doi.org/10.1111/cwe.12186

Yue, K., \& Zhang, K. H. (2014). How much does China's exchange rate affect the U.S. trade deficit? The Chinese Economy, 40(6), 80-93.

Zeileis, A., Leisch, F., Hornik, K., \& Kleiber, C. (2005). Monitoring structural change in dynamic econometric models. Journal of Applied Econometrics, 20, 99-121. https://doi.org/10.1002/jae.776

\section{Copyrights}

Copyright for this article is retained by the author(s), with first publication rights granted to the journal.

This is an open-access article distributed under the terms and conditions of the Creative Commons Attribution license (http://creativecommons.org/licenses/by/4.0/). 